www.mdpi.com/journal/applsci

Review

\title{
Sustainable Utility of Magnetically Recyclable Nano-Catalysts in Water: Applications in Organic Synthesis
}

\section{Manoj B. Gawande ${ }^{1, \dagger}, *$, Anuj K. Rathi ${ }^{2}$, Paula S. Branco ${ }^{1}$ and Rajender S. Varma ${ }^{3, *}$}

1 REQUIMTE, Department of Chemistry, Faculdade de Ciências e Tecnologia, Universidade Nova de Lisboa, Quinta da Torre 2829-516 Caparica, Portugal; E-Mail: paula.branco@fct.unl.pt

2 Jubilant Chemsys Ltd., B-34, Sector-58, Noida-201301, New Delhi, India;

E-Mail: anujr2@yahoo.co.in

3 Sustainable Technology Division, National Risk Management Research Laboratory, US Environmental Protection Agency, MS 443, 26 West Martin Luther King Drive, Cincinnati, OH 45268, USA

$\dagger$ Present Address: Regional Centre of Advanced Technologies and Materials, Faculty of Science, Department of Physical Chemistry, Palacky University, Olomouc, 17. listopadu 12, Olomouc 771 46, Czech Republic.

* Authors to whom correspondence should be addressed; E-Mails: mbgawande@yahoo.co.in or manoj.gawande@upol.cz (M.B.G.); varma.rajender@epa.gov (R.S.V.);

Tel.: +420-585-634-385 (M.B.G.); +1-513-487-2701 (R.S.V.).

Received: 20 June 2013; in revised form: 2 October 2013 / Accepted: 17 October 2013 /

Published: 25 October 2013

\begin{abstract}
Magnetically recyclable nano-catalysts and their use in aqueous media is a perfect combination for the development of greener sustainable methodologies in organic synthesis. It is well established that magnetically separable nano-catalysts avoid waste of catalysts or reagents and it is possible to recover $>95 \%$ of catalysts, which is again recyclable for subsequent use. Water is the ideal medium to perform the chemical reactions with magnetically recyclable nano-catalysts, as this combination adds tremendous value to the overall benign reaction process development. In this review, we highlight recent developments inthe use of water and magnetically recyclable nano-catalysts (W-MRNs) for a variety of organic reactions namely hydrogenation, condensation, oxidation, and Suzuki-Miyaura cross-coupling reactions, among others.
\end{abstract}


Keywords: magnetically recyclable nano-catalysts; aqueous medium; organic synthesis; sustainable methodologies

\section{Introduction}

Organic synthetic reactions have accepted the importance and urgency of magnetically recyclable nano-catalysts (MRNCs) in the development of clean methodologies during the last 5 years. Magnetic nano-catalysts have been studied in various significant protocols in organic chemistry because they are inexpensive, robust, and can be easily prepared often from base metal, iron, and most importantly can be recycled for several runs without any loss of selectivity and activity of catalysts [1-15].

In recent years, various greener solvents have been explored (with MRNCs) for a variety of sustainable organic protocols [16-20]. Organic reactions in aqueous medium without use of any harmful organic solvents are of utmost interest, because water is an easily available, economical, safe and environmentally benign solvent [21-25]. Magnetically recyclable nano-catalysts are a prime choice for chemists as they are easy to handle. Not surprisingly, the focus has been on the design and development of procedures using benign solvent (water) and magnetical nano-catalysts which reduces the waste at the end of reactions [26-32]. In this review, we discuss the fusion of aqueous media and MRNCs in the application of organic synthesis (Figure 1).

Figure 1. Tuning of water and magnetic nanoparticles.

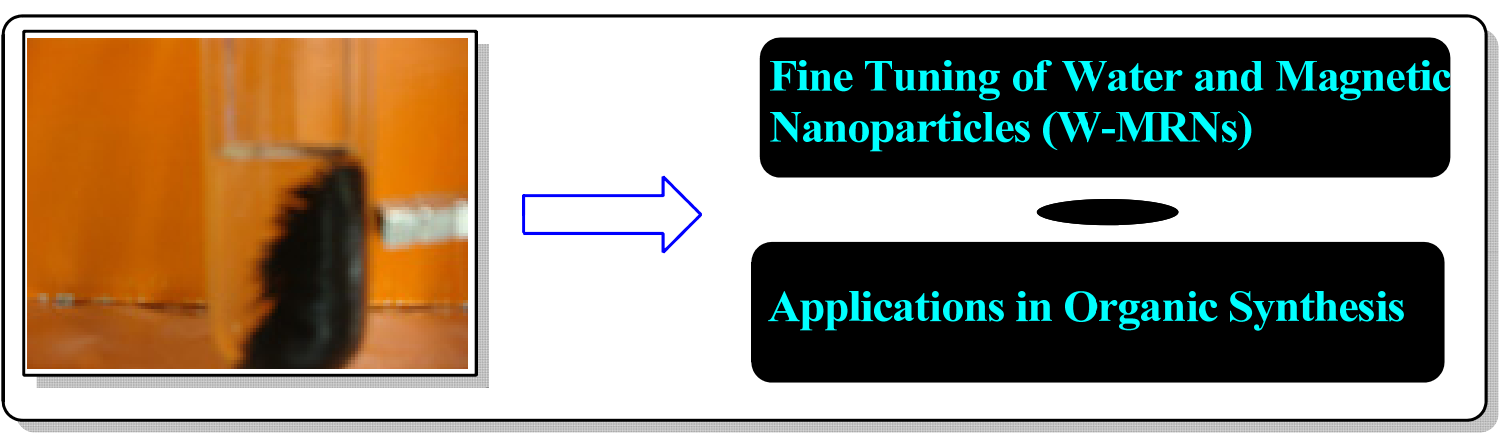

\section{Highlights of the Review}

Various magnetically recyclable supports such as magnetite $\left(\mathrm{Fe}_{3} \mathrm{O}_{4}\right)$, maghemite $\left(\gamma-\mathrm{Fe}_{2} \mathrm{O}_{3}\right)$, and $(\mathrm{Fe})$ iron metal are employed in the synthesis of nano-catalysts. Numerous metals, organocatalysts, or reagents are immobilized on magnetically separable support and their applications for a variety of catalytic processes organic reactions are presented including their preparation. The characterization of synthesized MRNCs is not discussed in this review and no results of any spectroscopic or analytical techniques are presented as they are adequately defined in the original papers and are out of the scope of this article. A few selected SEM and TEM images and particle size are included for representative schemes. 


\section{Applications of Magnetically Recyclable Nanocatalysis (MRNCs) in Water}

Pyrrole and their derivatives are one of the most imperative modules of nitrogen-containing heterocyclic compounds as they constitute the core unit of various natural products, active pharmaceutical ingredients and medicinal chemistry [33].

Zhang and coworkers have reported the magnetic nanoparticle $\left(\gamma-\mathrm{Fe}_{2} \mathrm{O}_{3}\right)$-supported antimony $(\mathrm{Sb})$ catalyst prepared by $\mathrm{Sb}$ containing ionic liquid via multistep synthesis procedure as depicted below (Scheme 1) [34].

Scheme 1. Synthesis of $\gamma-\mathrm{Fe}_{2} \mathrm{O}_{3} @ \mathrm{SiO}_{2}-\mathrm{Sb}-\mathrm{IL}$.
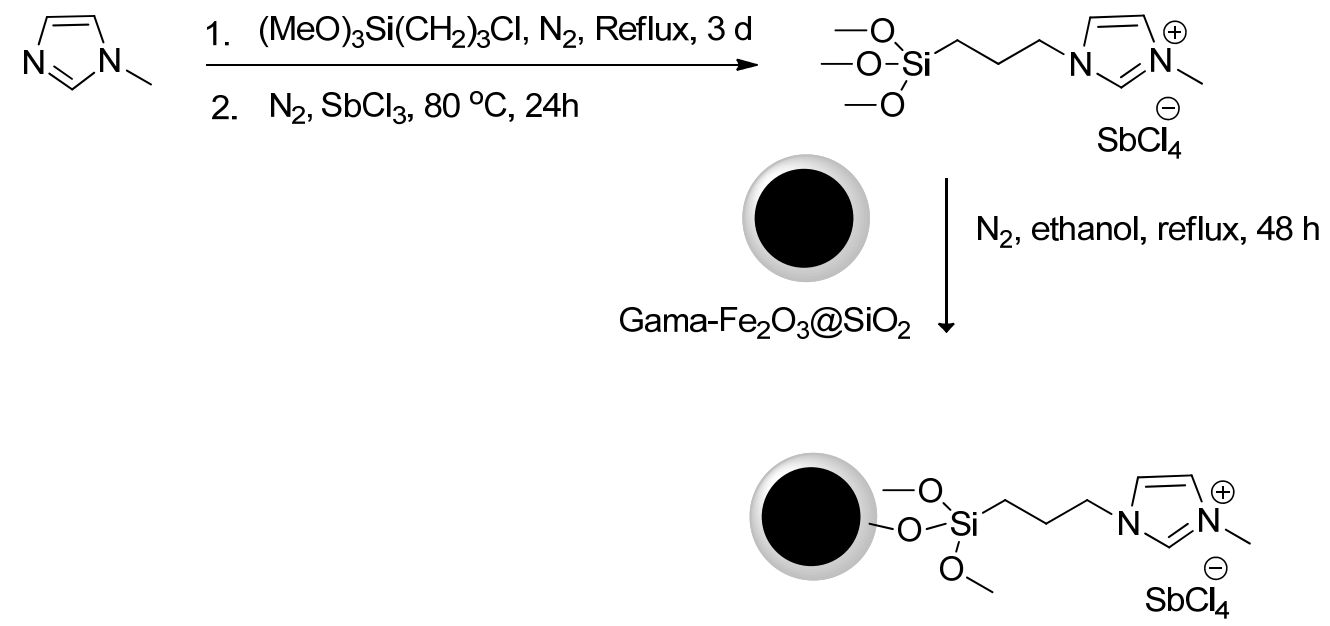

Gama- $\mathrm{Fe}_{2} \mathrm{O}_{3} @ \mathrm{SiO}_{2}-\mathrm{Sb}-\mathrm{IL}$

The as-synthesized and well characterized MRNCs (size $30 \mathrm{~nm}$, by SEM) were further employed for the synthesis of $N$-substituted pyrroles in moderate to excellent yield (Scheme $2 ; 55 \%-96 \%$ ).

Scheme 2. Synthesis of $N$-substituted pyrroles.

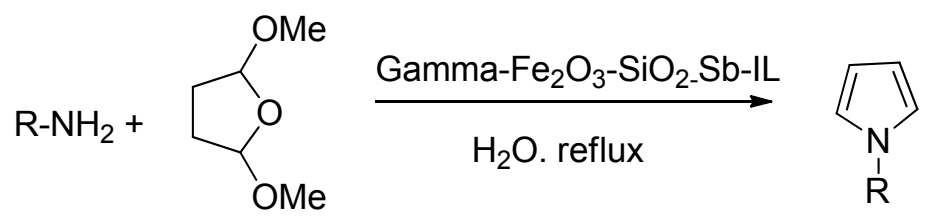

$55-96 \%$

42 examples

This simple and facile methodology using magnetic-supported antimony ionic liquid nanocatalysts $\left(\gamma-\mathrm{Fe}_{2} \mathrm{O}_{3} @ \mathrm{SiO}_{2}-\mathrm{Sb}-\mathrm{IL}\right)$, for Clauson-Cass reaction of amines to 2,5-dimethoxy-tetrahydrofurans worked in excellent fashion. It is interesting to note that its individual component forms such as $\gamma-\mathrm{Fe}_{2} \mathrm{O}_{3}$, and $\gamma-\mathrm{Fe}_{2} \mathrm{O}_{3} @ \mathrm{SiO}_{2}$ worked for this reaction, but better catalytic activity was found with $\gamma-\mathrm{Fe}_{2} \mathrm{O}_{3} @ \mathrm{SiO}_{2}-\mathrm{Sb}-\mathrm{IL}$ under optimized reaction conditions.

Superparamagnetic nanoparticle-supported $(S)$-diphenylprolinol trimethylsilyl ether has been employed for the asymmetric Michael-addition in aqueous media [35]. Jørgensen-Hayashi catalyst 
((S)-diphenylprolinol trimethylsilyl ether) on silica superparamagnetic nanoparticle support (MNP-JHC) was prepared by multistep synthetic procedure [35] (Figure 2).

Figure 2. MNP-supported Jørgensen-Hayashi Catalyst (MNP-JHC).

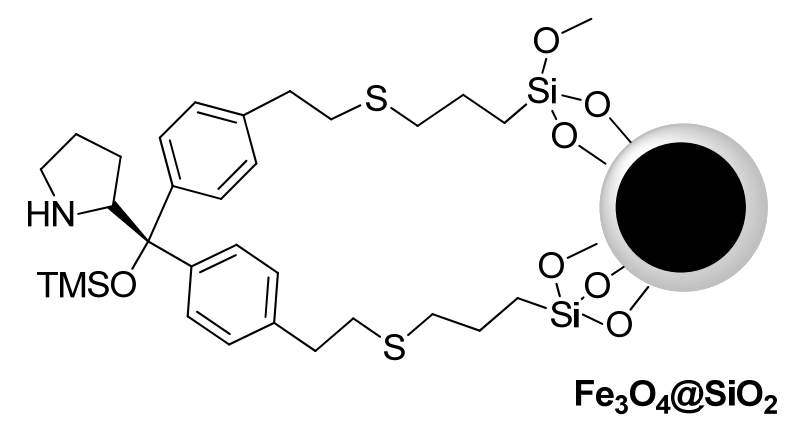

The as-synthesized and well characterized MNP-supported Jørgensen-Hayashi catalyst was employed for the asymmetric Michael addition of enolisable aldehydes to nitroalkenes in aqueous media, which gives corresponding products in moderate to good yields (up to 96\%), and good enantioselectivity (up to $90 \%$ ee) (Scheme 3).

Scheme 3. Asymmetric Michael addition of aldehydes to nitroalkenes in aqueous media using MNP-JHC.

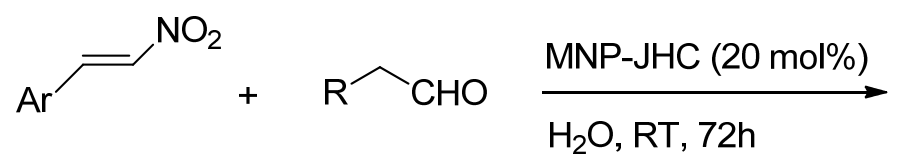

$\mathrm{H}_{2} \mathrm{O}, \mathrm{RT}, 72 \mathrm{~h}$<smiles>[R]C(C=O)C(Br)C[N+](=O)[O-]</smiles>

53-96 \%

Enantioselectivity up to $90 \%$ ee Diasteroselectivity up to (99:1)

13 examples

It is important to note that the reactions successfully worked in water to deliver $85 \%$ yield of the product for the model reaction between propanal and trans $\beta$-nitrostyrene. A variety of nitroalkanes and aldehydes were investigated under the optimized reactions conditions and the corresponding products were obtained in good to excellent yields in water.

Magnetite-supported $\mathrm{Pd}$ nanocatalysts was employed for the $O$-allylation of phenols with allylic acetates in aqueous media by Varma et al. [36]; allylic ethers are important precursors for various pharmaceutical products and drug intermediates, especially as protecting group [37]. Generally, allyl ethers are obtained by Williamson-type ether synthesis, which requires strong basic metal oxides anions and active allyl halides [38]. Magnetite-supported Pd nanocatalyst was prepared by anchoring dopamine ligand under sonication, following by the addition of Pd salts under basic medium as depicted in Scheme 4. 
Scheme 4. Synthesis of $\mathrm{Fe}_{3} \mathrm{O}_{4}$-Dopa-Pd nanocatalyst.
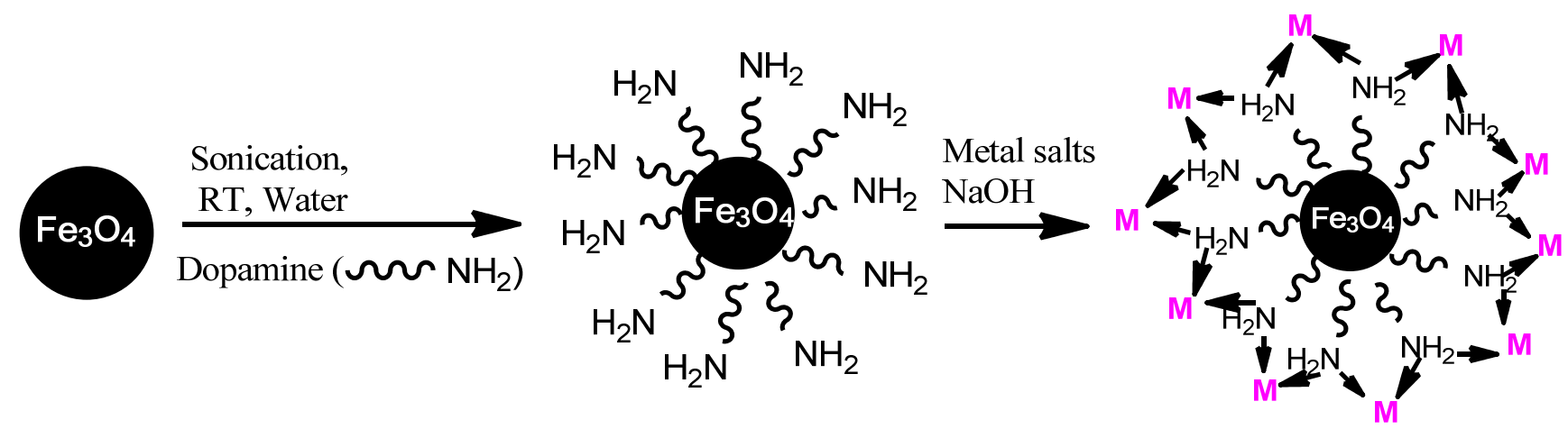

Where $\mathrm{M}=\mathrm{Pd}$

The spherical morphology and the size of the nano catalyst $(13-38 \mathrm{~nm})$ were confirmed by transmission electron microscopy (TEM) (Figure 3). The weight percentage of palladium metal was determined to be $10.23 \%$ by inductively coupled plasma-atomic emission spectroscopy (ICP-AES) analysis.

Figure 3. TEM image of $\left[\mathrm{Fe}_{3} \mathrm{O}_{4}-\right.$ dopa-Pd] catalyst. Reprinted with permission from [36]. Copyright 2012 Royal Society of Chemistry.

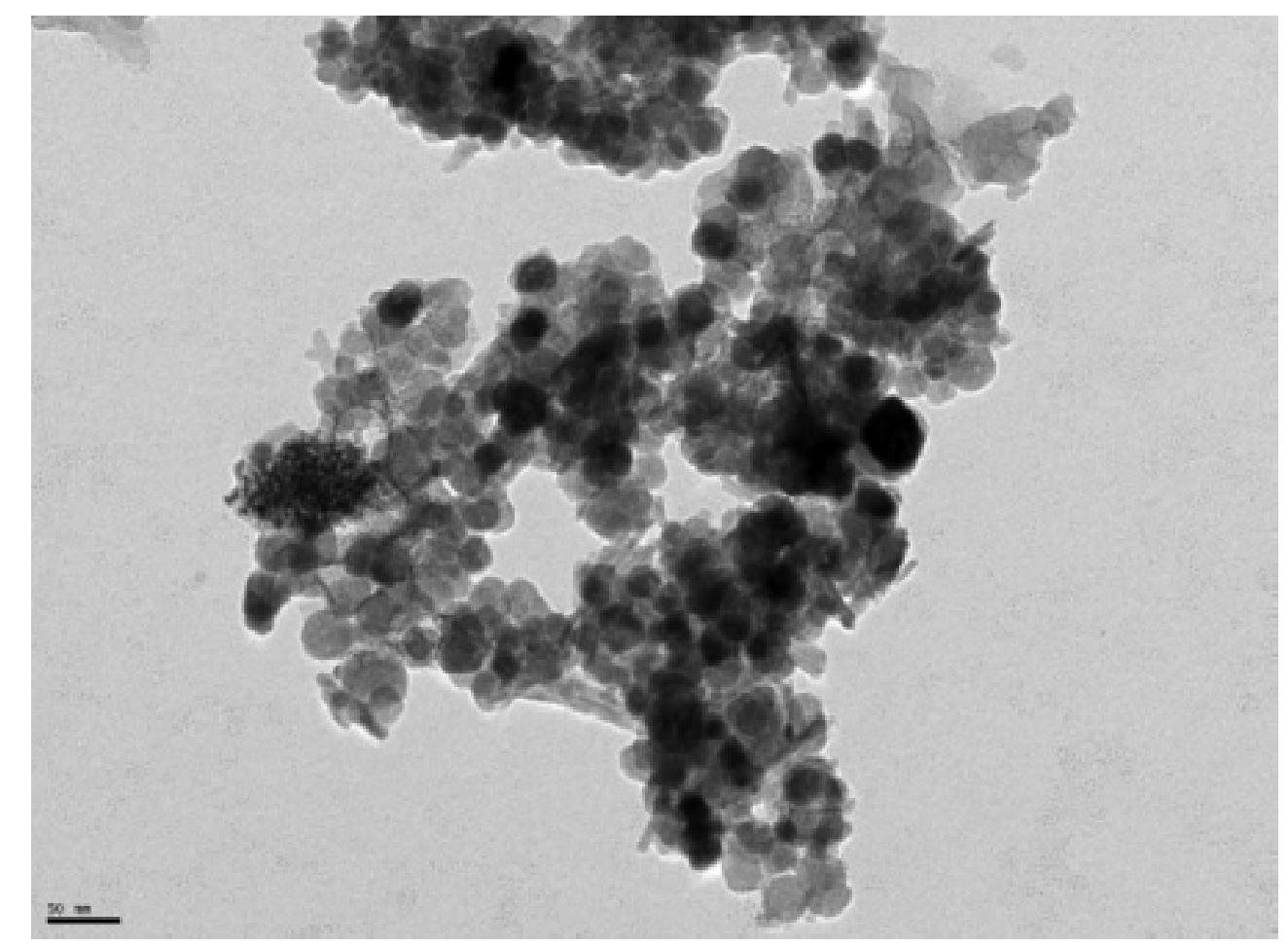

The $\mathrm{Fe}_{3} \mathrm{O}_{4}$-Dopa-Pd nanocatalysts used for the $O$-allylation of phenols with allylic acetates in water under mild reaction conditions (Scheme 5). 
Scheme 5. $\mathrm{Fe}_{3} \mathrm{O}_{4}$-Dopa-Pd catalyzed $O$-allylation of phenol in aqueous medium.

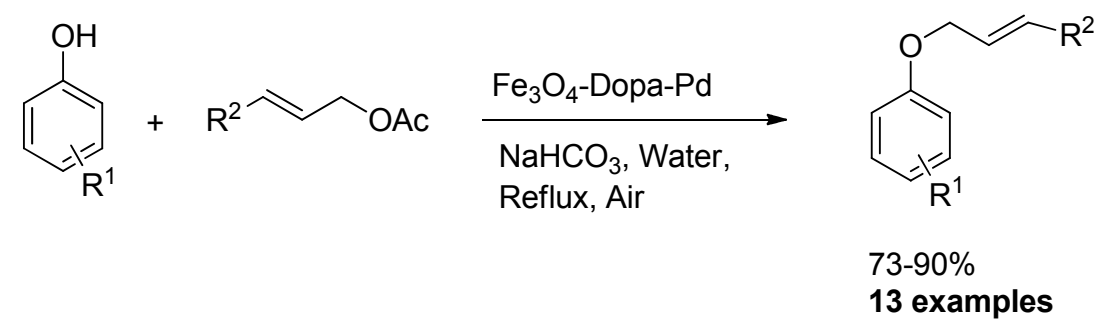<smiles>C(=Cc1ccccc1)c1ccccc1</smiles>

$80 \%$<smiles>Cc1ccccc1OC/C=C/c1ccccc1</smiles>

$83 \%$<smiles>Br/C=C/COc1ccccc1Br</smiles>

$85 \%$<smiles>Cc1ccc(OC/C=C/c2ccccc2)cc1</smiles>

$85 \%$<smiles>C=CCOc1ccc(C)cc1</smiles>

$90 \%$<smiles>C(=Cc1ccccc1)COc1cccc2ccccc12</smiles>

$75 \%$<smiles>Cc1cccc(OC/C=C/c2ccccc2)c1</smiles>

$87 \%$<smiles>Cc1ccc(/C=C/COc2ccc(C)cc2)cc1</smiles>

$76 \%$<smiles>Clc1ccc(OC/C=C/c2ccccc2)c(Cl)c1</smiles>

$79 \%$

A variety of cinnamyl acetate reacted with phenols under optimized reaction conditions to deliver the desired products in the good to excellent yield (73\%-90\%). The Pd metal content, determined by ICP-AES, did not leach during the reaction, which clearly indicates that the catalyst is truly in a heterogeneous form.

Luque and co-workers reported mesoporous silica supported iron oxide nanoparticles for the oxidation of alkenes using hydrogen peroxide in aqueous medium [39]. Supported iron oxides nanocatalysts have been the focus in various important catalytic applications because of their low cost and toxicity, ready availability, and environmentally benign nature [6,40]. Styrenes and their substituted derivatives are converted to respective aldehydes in excellent yield (Scheme 6). It is important to note that no other side products or oxidations of aldehydes were observed during the reaction. The optimized protocol was suitable to a range of electron-withdrawing and electron-donating substituents localized in all positions of the aromatic ring. 
Scheme 6. Mesoporous silica supported iron oxide nanoparticles for the oxidation of alkenes using hydrogen peroxide in aqueous medium.

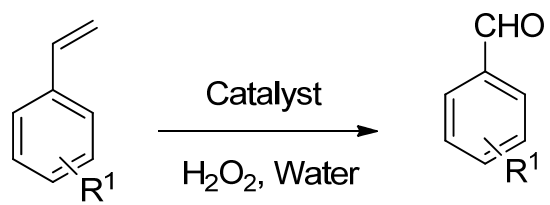<smiles>O=Cc1ccccc1</smiles>

$95 \%$<smiles>O=Cc1ccc(Cl)cc1</smiles>

$90 \%$<smiles>O=Cc1ccc(F)cc1</smiles>

$92 \%$<smiles>O=Cc1ccc(CCl)cc1</smiles>

$92 \%$<smiles>O=Cc1ccc(Br)cc1</smiles>

$90 \%$<smiles>O=Cc1ccccn1</smiles>

95\%<smiles>O=Cc1cccc(Cl)c1</smiles>

$90 \%$<smiles>COc1ccccc1C=O</smiles>

$93 \%$

Magnetite-supported biguanide/ $\mathrm{Pd}(\mathrm{OAc})_{2}$ ligand has been employed as a recyclable catalyst for the heterogeneous Suzuki reaction in aqueous media [41]. The palladium-catalyzed Suzuki reaction is a most attractive and useful methodology for carbon-carbon bond formation [42]. In general, Suzuki reactions are usually catalyzed by homogeneous palladium catalysts or palladium salts and also by using Pd colloids and supported Pd catalysts [43]. However, these types of homogeneous catalysts could not be reused and are expensive as well. Immobilization of $\operatorname{Pd}(\mathrm{II})$ ions on magnetite support has been achieved via surface modification of $\mathrm{Fe}_{3} \mathrm{O}_{4}$ nanoparticles with a biguanide (Scheme 7).

Scheme 7. Synthesis of magnetite-supported biguanide/ $\mathrm{Pd}(\mathrm{OAc})_{2}$ ligand.

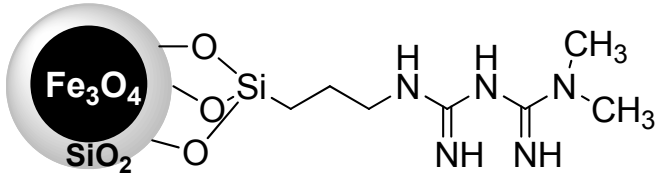<smiles>CCOC(=O)OCCOC(=O)OCCOCCO</smiles>
$8 \mathrm{~h}$

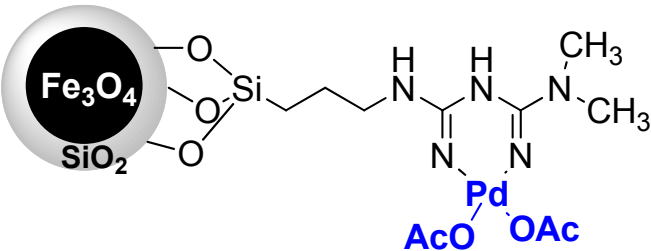

Magnetite-Biguanide/Pd(OAc) 2

This magnetite-supported biguanide/ $\mathrm{Pd}(\mathrm{OAc})_{2}$ nano-catalyst ( $40-45 \mathrm{~nm}$ by TEM) exhibits excellent catalytic activity for heterogeneous Suzuki reaction in aqueous media, and could be easily separated by an external magnet and recycled for several runs (Scheme 8). 
Scheme 8. Magnetite-supported biguanide/ $\mathrm{Pd}(\mathrm{OAc})_{2}$ catalyzed Suzuki reaction in aqueous medium.

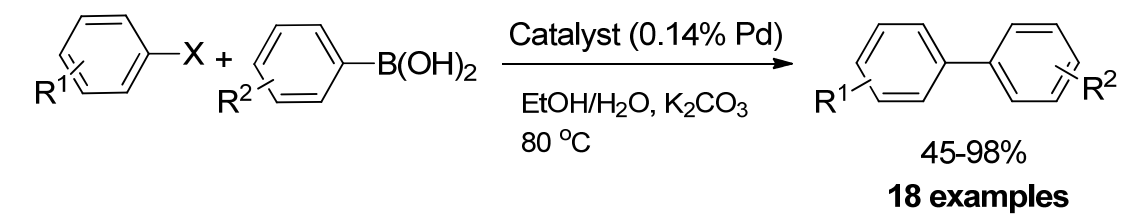

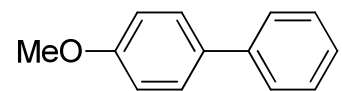

$94 \%$

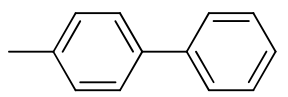

$97 \%$<smiles>c1ccc(-c2cccc3ccccc23)cc1</smiles>

$92 \%$

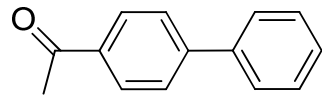

$97 \%$

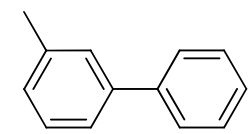

$85 \%$

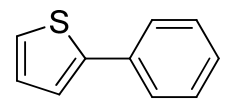

$94 \%$

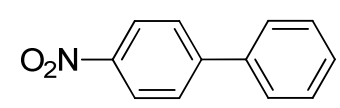

$94 \%$

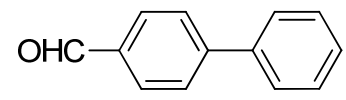

$92 \%$

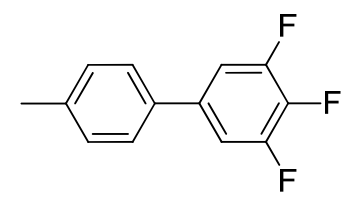

$96 \%$

Importantly, the coupling reaction of deactivated boronic acids; 3-nitrophenyl and 3,4,5,-triflourobenezeneboronic acid with bromobenzene and 4-bromobenzaldehyde gave the corresponding products in $95 \%, 88 \%, 94 \%$ and $95 \%$ yields, respectively.

Liu et al. reported one-pot, three-component synthesis of a spirooxindole-pyrimidines and its derivatives using magnetic nanoparticle supported dodecyl benzenesulfonic acid (DDBSA) in aqueous medium [44]; spirooxindoles-pyrimidines are important heterocyclic moieties, part of natural products and have wide range of applications in medicinal chemistry. The $\gamma-\mathrm{Fe}_{2} \mathrm{O}_{3} @ \mathrm{SiO}_{2}-\mathrm{DDBSA}$ nanocatalyst was prepared by a reported procedure [44] wherein $\gamma-\mathrm{Fe}_{2} \mathrm{O}_{3}$ was first prepared, then coated by silica using tetraethyl orthosilicate (TEOS), followed by addition of DDBSA (Scheme 9).

Scheme 9. Synthesis of $\gamma-\mathrm{Fe}_{2} \mathrm{O}_{3} @ \mathrm{SiO}_{2}$-DBSA.

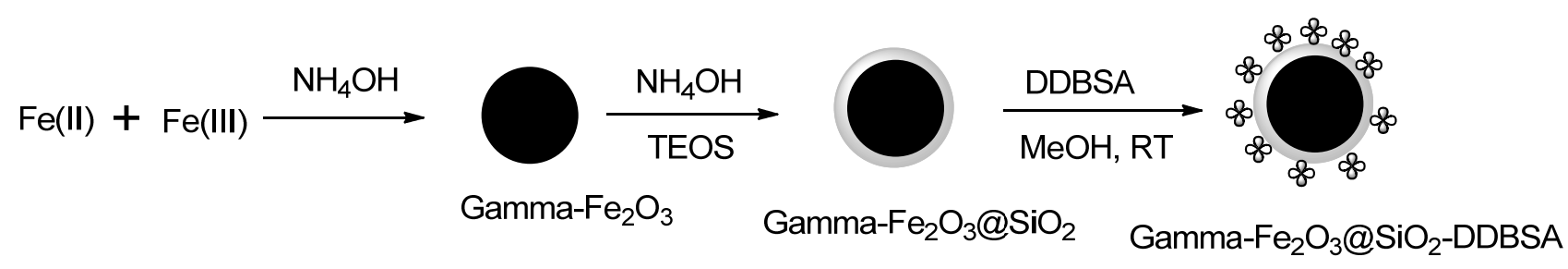

The synthesis of spirooxindole-pyrimidines derivatives was achieved by a one-pot three-component reaction of barbituric acids, isatins, and cyclohexane-1,3-diones in aqueous medium catalyzed by $\gamma-\mathrm{Fe}_{2} \mathrm{O}_{3} @ \mathrm{SiO}_{2}$-DDBSA. The desired products were obtained in good to excellent yields with the characteristic ease of isolation procedure; $\gamma-\mathrm{Fe}_{2} \mathrm{O}_{3} @ \mathrm{SiO}_{2}$-DDBSA nano-catalysts could be reused up to 6 times (Scheme 10). 
Scheme 10. Synthesis of Spirooxindole-Pyrimidines derivatives.

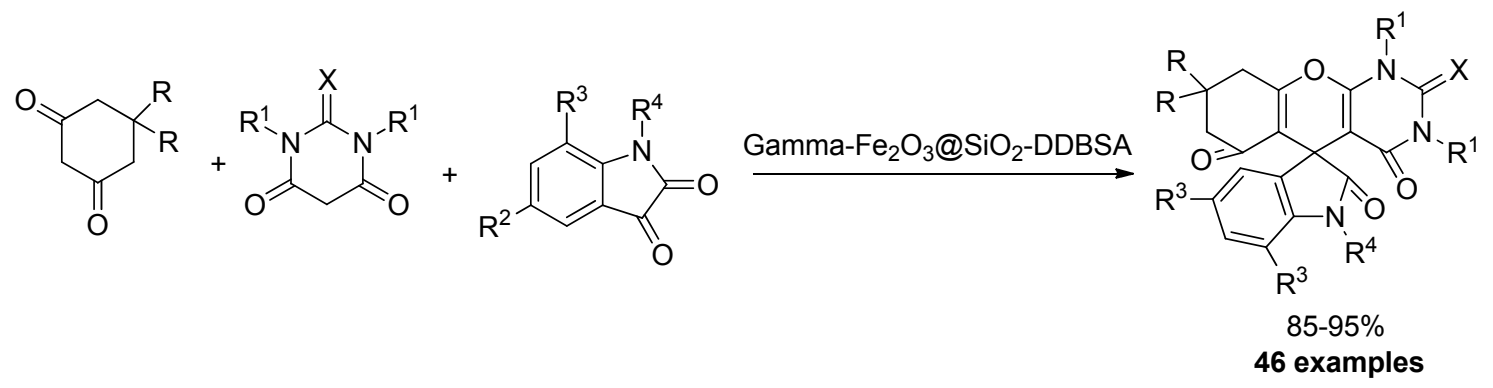

Cyclohexane-1,3-diones

Barbityric acid<smiles>CC1(C)CC(=O)CC(=O)C1</smiles><smiles>O=C1CCCC(=O)C1</smiles><smiles>O=C1CC(=O)NC(=O)N1</smiles><smiles>CN1C(=O)CC(=O)N(C)C1=O</smiles><smiles>O=C1CC(=O)NC(=S)N1</smiles>

Isatins<smiles>O=C1Nc2ccccc2C1=O</smiles><smiles>Cc1ccc2c(c1)C(=O)C(=O)N2</smiles><smiles>Cc1cc2c(c([N+](=O)[O-])c1)NC(=O)C2=O</smiles><smiles>O=C1Nc2ccc(F)cc2C1=O</smiles>

The selective oxidation of primary and secondary alcohols is an important and challenging reaction in the organic synthesis [45]. Various oxidizing reagents such as stoichiometric $\mathrm{Cr}^{\mathrm{IV}}$ salts [46], hypervalent iodine [47] and DMSO-coupled reagents are often employed for these reactions. However, they show poor atom efficiency and are often toxic; their frequent use causes a significant environmental damage. Therefore, it is imperative to design new benign reagents for the selective oxidation of alcohols. Karimi et al. reported magnetite-supported TEMPO nanocatalysts for metal-free and halogen-free oxidation of primary and secondary alcohols in aqueous medium [48]; the catalyst was synthesized by a multistep procedure starting from magnetite (Scheme 11).

Scheme 11. Synthesis of magnetite-supported TEMPO nanocatalyst.
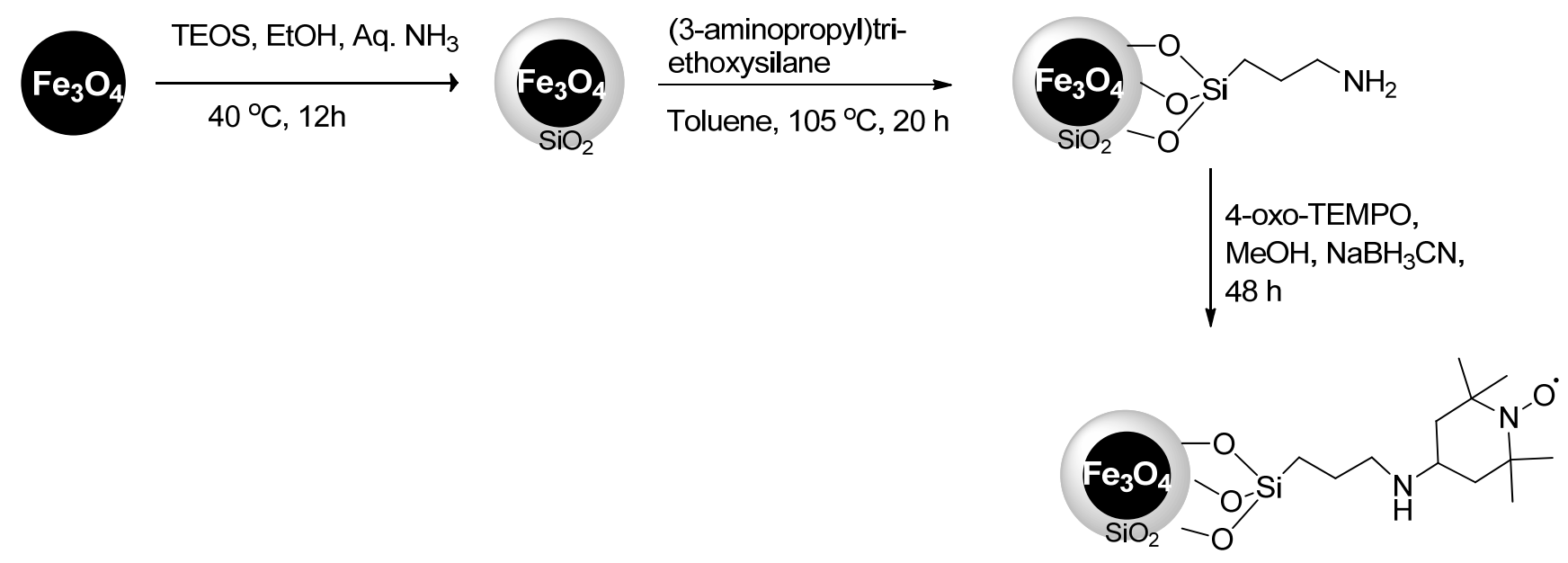
Magnetite-supported TEMPO nanocatalyst worked well for an array of alcohols (primary, secondary, air sensitive and sterically hindered alcohols), and all substrates are converted to the corresponding carbonyls in good to excellent yields (Scheme 12).

Scheme 12. Selective oxidation of alcohols catalyzed by magnetite-supported TEMPO.

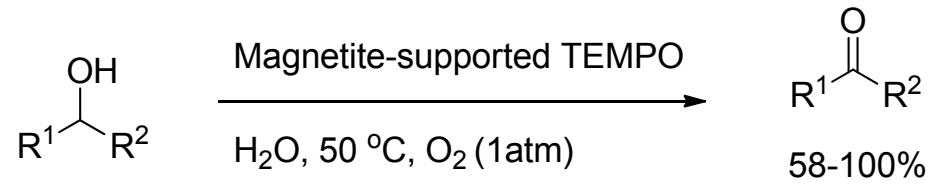

33 examples<smiles>O=Cc1ccccc1</smiles>

$100 \%$<smiles>O=Cc1ccc(Cl)cc1</smiles>

$100 \%$<smiles>O=Cc1cccc(Cl)c1</smiles>

$100 \%$<smiles>O=Cc1ccc(Cl)cc1Cl</smiles>

$100 \%$<smiles>O=Cc1ccc([N+](=O)[O-])cc1</smiles>

$92 \%$<smiles>CC(=O)c1ccccc1</smiles>

$100 \%$<smiles>CCC(=O)c1ccccc1</smiles>

$89 \%$<smiles>O=C(c1ccccc1)c1ccccc1</smiles>

$80 \%$

This highly efficient, metal- and halogen-free protocol could be used for the preparation of important pharmaceutical raw materials and drug intermediates.

Kiasat and Nazari have synthesized $\beta$-cyclodextrin-polyurethane polymer decorated $\mathrm{Fe}_{3} \mathrm{O}_{4}$ magnetic nanoparticles ( $\beta$-CDPU-MNPs) as a novel class of hybrid organic/inorganic molecular catalyst in two steps and evaluated their performance for solid-liquid phase-transfer catalyst in nucleophilic substitution reactions of benzyl halides in water [49]. First, superparamagnetic magnetite nanoparticles (MNPs) were prepared via chemical coprecipitation method [50] and then decorated by $\beta$-cyclodextrin-polyurethane (CDPU) polymer. The $\beta$-CDPU-MNPs (17-20 nm by TEM) was employed for the nucleophilic substitution reaction of benzyl halides with thiocyanate; acetate anions, azides, and cyanides; excellent yield of the corresponding products were obtained (Scheme 13).

The desired products were obtained in pure form which does not require further purification and the formation of by-products such as isothiocyanate or alcohols was not discernible; nanomagnetic $\beta$-CDPU catalyst was easily separable from reaction mixture via application of a magnetic field, allowing straightforward recovery and reuse. 
Scheme 13. Nucleophilic substitution reaction of benzyl halides with thiocyanate, azide, cyanide, and acetate anions in water.

$$
\begin{array}{lll}
\text { Water, } 90^{\circ} \mathrm{C} \\
\mathrm{Y}=\mathrm{SCN}, \mathrm{CN}, \mathrm{N}_{3}, \mathrm{OAC}
\end{array}
$$

Benzyl halides<smiles>BrCc1ccccc1</smiles><smiles>ClCc1ccc(Cl)cc1Cl</smiles><smiles>BrCc1ccc(Br)cc1</smiles><smiles>COc1cccc(CCl)c1</smiles>

Fujii and co-workers have investigated a facile synthesis of magnetic-iron grafted polymer-palladium ternary nanocomposite microspheres $[(\mathrm{Fe})-\mathrm{PPy}-\mathrm{Pd}]$ via the aqueous chemical oxidative polymerization of pyrrole, using $\mathrm{PdCl}_{2}$ as the oxidant in the presence of Fe nanoparticles [51]. In typical synthesis of [(Fe)-PPy-Pd], carbon-coated magnetic $\mathrm{Fe}(\mathrm{Fe} / \mathrm{C})$ nanoparticles were synthesized by an arc plasma method. The carbon shell was introduced to prevent oxidation of $\mathrm{Fe}$ and then oxidative polymerization of pyrrole was achieved by employing $\mathrm{PdCl}_{2}$ as an oxidant (Scheme 14).

Scheme 14. Synthesis of (Fe)-PPy-Pd.

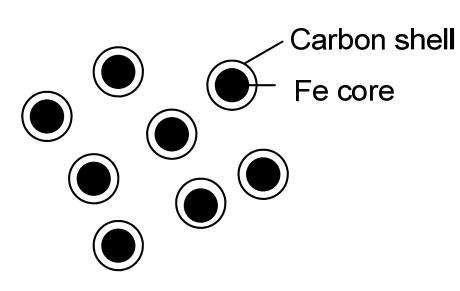

Fe/C magnetic nanoparticles

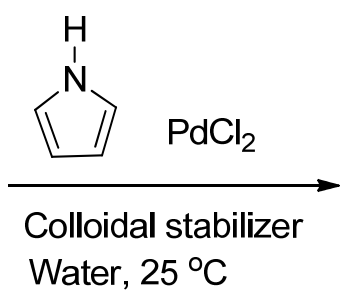

\section{Magnetic Fe-PPy-Pd ternary nanocomposite microspehere}

The catalytic performance of $(\mathrm{Fe})-\mathrm{PPy}-\mathrm{Pd}(14.6 \pm 7.9 \mu \mathrm{m})$ for the Suzuki-Miyaura cross-coupling reaction between p-methylphenylboronic acid and p-bromoacetophenone in aqueous media was investigated to generate 4-acetyl-4'-methylbiphenyl (98\% yield). After the completion of this first reaction, (Fe)-PPy-Pd were recovered using a magnetic bar and reused for four successive cycles for the coupling reaction under the same conditions, affording the product in $99 \%, 99 \%, 94 \%$, and $99 \%$ yields, respectively. In addition, ICP-AES results indicated little to no leaching of the Pd from the (Fe)-PPy-Pd after the fifth reaction.

Kale and Jayaram have reported magnetically retrievable $\gamma-\mathrm{Fe}_{2} \mathrm{O}_{3} /$ hydroxyapatite (HAP) nanoparticles for the cycloaddition reactions of alkyne, halide and azide in aqueous medium to 1,2,3-triazoles [52]. In general, these types of reactions are performed using $\mathrm{Cu}$ and $\mathrm{Ru}$ metal bearing catalysts [53,54]. Recently, magnetically recyclable copper-supported magnetic nanoparticles have been investigated for the synthesis of disubstituted 1,2,3-triazoles [55,56]. It is important to replace these non-recyclable 
and expensive metals by base metal such as iron. In typical synthesis of $\gamma-\mathrm{Fe}_{2} \mathrm{O}_{3} / \mathrm{HAP}$, the iron nanoparticle supported on HAP were prepared by simple co-precipitation method [52].

The TEM images $(10-35 \mathrm{~nm})$ of the fresh catalyst and recovered catalyst after fifth cycle are depicted in Figure 4, indicating no change in the morphology of the $\gamma-\mathrm{Fe}_{2} \mathrm{O}_{3} / \mathrm{HAP}$ nanocatalyst.

Figure 4. TEM images of the $\gamma-\mathrm{Fe}_{2} \mathrm{O}_{3}-\mathrm{HAP}$ nanocatalyst: (a) "fresh" catalyst and (b) "recovered" catalyst after the fifth run. Reprinted with permission from [52]. Copyright 2012 Royal Society of Chemistry.
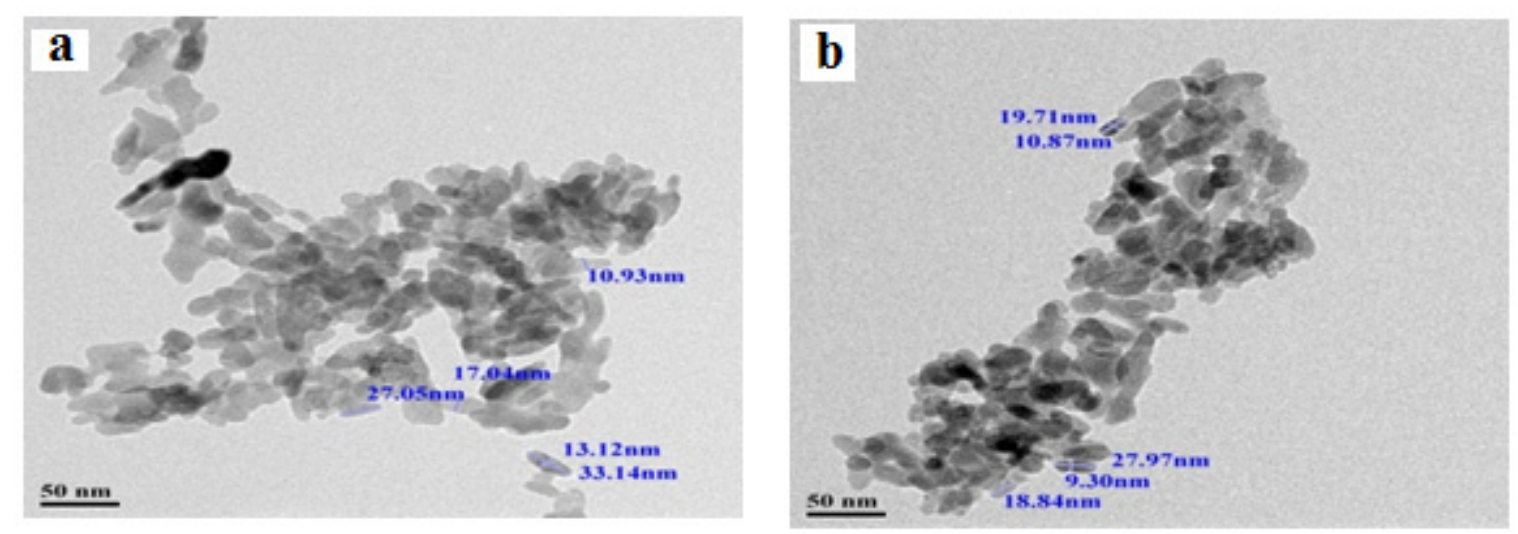

Scheme 15. $\gamma-\mathrm{Fe}_{2} \mathrm{O}_{3} / \mathrm{HAP}$ catalyzed cycloaddition reaction of alkynes, and in situ generated azides in water.

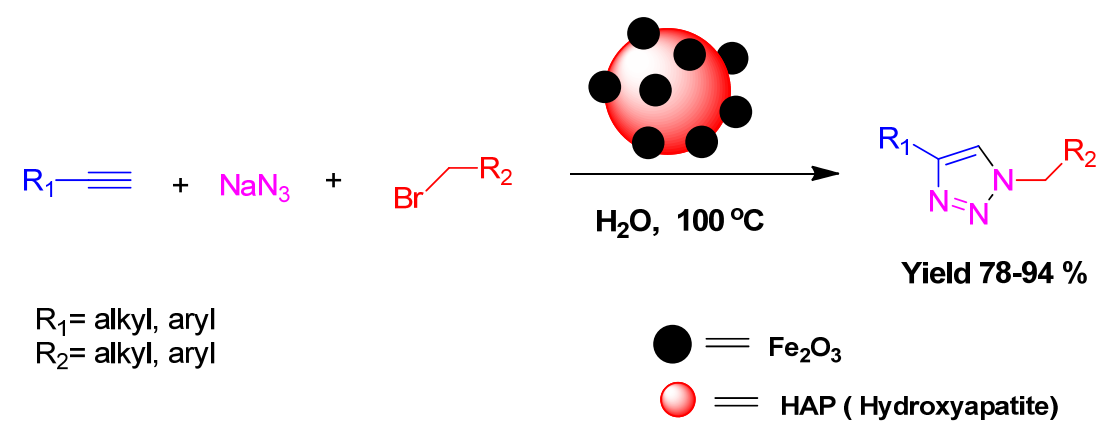

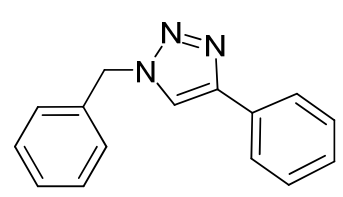

$94 \%$<smiles>CCOC(=O)Cn1cc(-c2ccccc2)nn1</smiles>

$91 \%$<smiles>Clc1ccccc1Cn1cc(-c2ccccc2)nn1</smiles>

$91 \%$<smiles>CC(C)(C)c1cn(Cc2ccccc2)nn1</smiles>

$78 \%$<smiles>Fc1ccccc1Cn1cc(-c2ccccc2)nn1</smiles>

$89 \%$<smiles>CCCCCc1cn(Cc2ccccc2)nn1</smiles>

$87 \%$ 
$\gamma-\mathrm{Fe}_{2} \mathrm{O}_{3} / \mathrm{HAP}$, was deployed in the synthesis of disubstituted 1,2,3-triazoles from terminal alkynes and in situ generated organic azide in aqueous media; this greener methodology emerges as a new approach for one-pot synthesis of 1,2,3-triazoles in water without the addition of any reagent/base (Scheme 15).

The use of an iron-based heterogeneous catalyst instead of the commonly used copper or ruthenium ones renders this methodology comparatively more economical, experimentally simple, and, therefore appealing for industrial use.

$\mathrm{Fe}_{3} \mathrm{O}_{4}-\mathrm{Pd}$ nanocomposite having core-satellite heterostructure, has been used for decarboxylative coupling reactions in aqueous media by Lee and co-workers [57]. The catalyst, $\mathrm{Fe}_{3} \mathrm{O}_{4}-\mathrm{Pd}$ nanocomposite having core-satellite heterostructure, was prepared by reactions of Pluronic polymer (P123, PEO19-PPO69-PEO19)-coated $\mathrm{Fe}_{3} \mathrm{O}_{4}$ nanoparticle and $\mathrm{Na}_{2} \mathrm{PdCl}_{4}$ as palladium source (Scheme 16).

Scheme 16. Synthesis of $\mathrm{Fe}_{3} \mathrm{O}_{4}-\mathrm{Pd}$ nanocomposite.
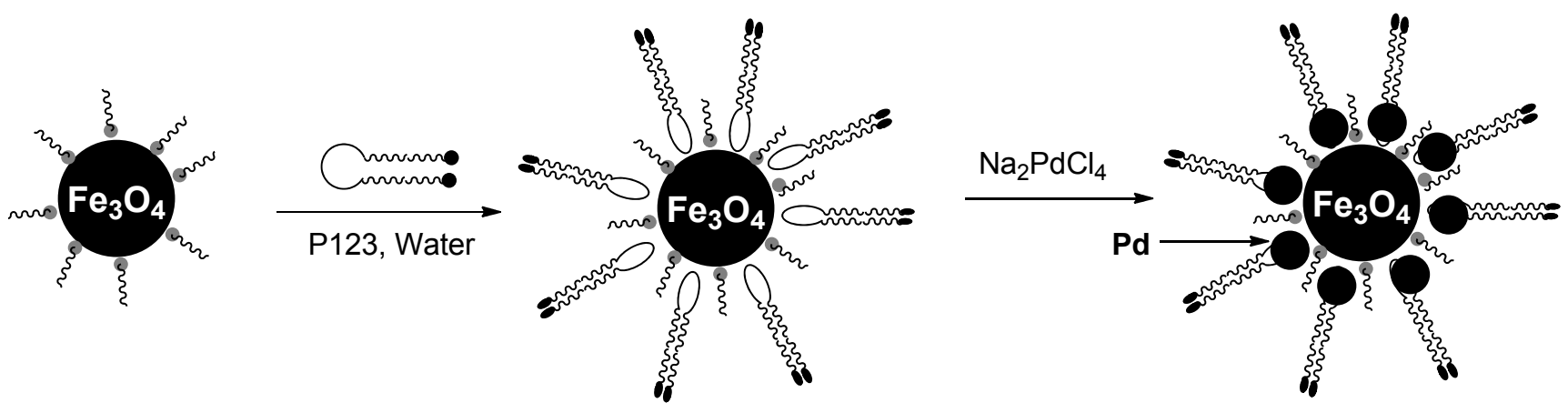

Notably, the nanoparticle surface stabilized by Pluronic copolymer would act as nanoreactors to help the solubility of organic reactants and permit the reactants to interact more intimately with the $\mathrm{Pd}$ nanoparticles. The activity and selectivity of $\mathrm{Fe}_{3} \mathrm{O}_{4}-\mathrm{Pd}$ MNPs ( $\mathrm{Pd}$ nanoparticles having 2:1 \pm 0:4 nm in average size around $\mathrm{Fe}_{3} \mathrm{O}_{4}$ nanoparticle and core-satellites heterostructure) were then investigated for the decarboxylic coupling reaction of allyl alkynoate, in aqueous media (Table 1).

Table 1. Catalytic decarboxylic coupling reaction of allyl alkynoate, in aqueous media.

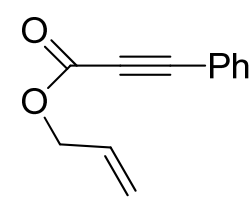

1

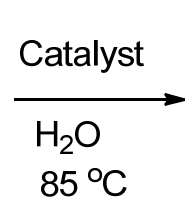

$85^{\circ} \mathrm{C}$

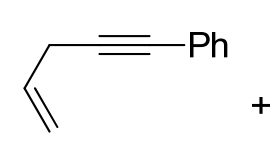

2

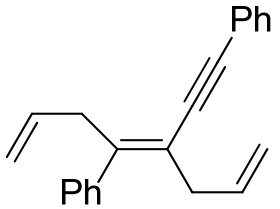

3

\begin{tabular}{ccccc}
\hline Entry & Catalyst & $\boldsymbol{T} /{ }^{\circ} \mathbf{C}$ & $\boldsymbol{t} / \mathbf{h}$ & Isolated Yield (\%) \\
\hline 1 & $5 \mathrm{~mol}^{2} \mathrm{Fe}_{3} \mathrm{O}_{4}-\mathrm{Pd}$ & 85 & 2 & $25(3)(70)^{\mathrm{a}}$ \\
2 & $5 \mathrm{~mol} \% \mathrm{Fe}_{3} \mathrm{O}_{4}-\mathrm{Pd}$ & 85 & 12 & $95(3)$ \\
3 & Recovered from entry 2 & 85 & 12 & $88(3)$ \\
4 & $5 \mathrm{~mol} \% \mathrm{Pd} / \mathrm{C}$ & 85 & 12 & $20(4(2): 1(3)){ }^{\mathrm{b}}$ \\
5 & $5 \mathrm{~mol} \% \mathrm{Pd}\left(\mathrm{PPh}_{3}\right)_{4}$ & 85 & 6 & $92(4(2): 1(3))^{\mathrm{b}}$ \\
\hline
\end{tabular}

${ }^{\mathrm{a}}$ Yield of the parentheses is of the recovered reactant; ${ }^{\mathrm{b}}$ The ratio was determined by ${ }^{1} \mathrm{HNMR}$. 
The reaction was performed by addition of a sparingly water-soluble substrate into an aqueous suspension of $\mathrm{Pd}-\mathrm{Fe}_{3} \mathrm{O}_{4}$, which showed good catalytic activity for 3-phenyl-2-propynoic acid 2-propenyl ester (3), providing 95\% yield of the decarboxylated product; commercially available Pd on charcoal afforded $20 \%$ yield, under the similar reaction condition. The treatment of 1 with $\left.\mathrm{Pd}_{(\mathrm{PPh}}\right)_{4}$ and $\mathrm{Pd}$ on charcoal gave a mixture of products 2 and 3 (Table 1). The activity and selectivity of the $\mathrm{Pd}-\mathrm{Fe}_{3} \mathrm{O}_{4}$ for catalyzing aqueous decarboxylative coupling reactions, avoids the use of hazardous organic solvent and ensure its easy reusability and recovery via magnetic separation.

Yamashita and co-workers have reported the catalytic activity of the FecorePtshell NPs capped with $\gamma$-cyclodextrin (CD) for hydrogenation reactions in aqueous medium [58]. The magnetically separable catalyst capped with $\gamma$-CD was synthesized from iron and Pt precursors to generate FePt NPs with Fe-rich core and Pt-rich shell, which renders them water-dispersible, rather than in organic solvents. The catalytic activity of FecorePtshell NPs capped with $\gamma$-CD was investigated for the aqueous hydrogenation reaction of $p$-nitrophenol and the corresponding $p$-aminophenols were obtained in excellent yield (Scheme 17).

Scheme 17. Reduction of p-nitrophenol in aqueous medium.<smiles>O=[N+]([O-])c1ccc(O)cc1</smiles>

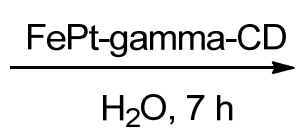<smiles>Nc1ccc(O)cc1</smiles>

Conv. $>99 \%$

Furthermore, the catalyst is highly selective on the hydrogenation reaction of allyl alcohols over more sterically hindered alkenes, which are probably related to the molecular recognition property imparted by the surface attached $\gamma-\mathrm{CD}$.

Recently, Li et al. reported asymmetric transfer hydrogenation of aromatic ketones in aqueous medium catalyzed by magnetically recoverable silica-supported $\mathrm{Fe}_{3} \mathrm{O}_{4}$-chiral rhodium catalysts [59].

Rezaeifard and Jafarpour have reported magnetically retrievable phthalocyanine nanocatalyst synthesized by immobilization of the $\mathrm{Cu}^{\mathrm{II}}$ phthalocyanine-tetrasulfonic acid tetrasodium complex $(\mathrm{CuPcS})$ on the silica coated magnetic nanoparticles $\left(\mathrm{Fe}_{3} \mathrm{O}_{4} @ \mathrm{SiO}_{2}\right)$ via amine functionality. The nano-catalyst was employed for the epoxidation of olefins and the oxidation of saturated hydrocarbons to corresponding ketones and sulfides to the sulfones in aqueous medium [60].

\section{Reusability of Magnetic Nanocatalysts}

Importantly, all these synthetic protocols were developed via 'benign by design concept and "Sustainable Chemistry" attributes, using eco-friendly solvents like water and non-conventional energy sources. Separation and recovery of the catalyst is an important aspect for the synthesis of fine chemicals, and pharmaceutical products which is often performed by filtration with reduced efficiency. In these catalytic systems, super-paramagnetic nature of the nano-catalyst enables their recovery by a simple external magnet, with high efficiency and up to $95 \%$ recovery. For practical applications of heterogeneous systems, the lifetime of the catalyst and its level of reusability are significant factors. 
This issue has been addressed in most of the reported methodologies thus establishing the heterogeneity of the catalysts and their recyclability; metal leaching of the catalysts has been examined by ICP-AES analysis.

\section{Conclusions and Future Perspectives}

In this review article, we have briefly summarized the magnetically retrievable supported nanocatalysts containing magnetite, maghemite, and iron which serve as a support to immobilize catalytically active metals via linkers or ligands. Additionally, various homogeneous organocatalysts such as TEMPO, and Jørgensen-Hayashi catalyst supported on silica-coated magnetite support provide an insight in to emerging area of organocatalysis, where separation can be accomplished easily thus saving on solvent usage for removal of such ligands in conventional reactions. The diversity of reactions, where such catalysts could be employed for the synthesis of heterocycles, Michael addition reaction, oxidation, reduction, multicomponent reaction or $\mathrm{C}-\mathrm{C}$ bond formation, attest to the importance of this area.

Magnetic separation technology is an important arena for separation and reuse of nano-catalysts and other functionalized solids. We believe that the surface functionalization and modification of magnetic nanoparticles to design new benign protocols will achieve new milestone in coming years. NHC-supported magnetite, multifunctional magnetic nanomaterials, with designed active sites, including complexes, enzymes, chiral catalysts and other species, are promising for a variety of applications. The main objective is to highlight greener and sustainable alternatives for various important organic reactions performed by magnetically separable catalysts in aqueous medium thus stimulating more applications that are imaginative. The use of water as a "green" solvent as well as easy and safe work-up procedure using an external magnet, coupled with the reusability of these catalysts renders the title methodology a cost effective option for several reactions thus making them suitable for large scale synthesis and wide range of potential industrial applications.

\section{Conflicts of Interest}

The authors declare no conflict of interest.

\section{References}

1. Gawande, M.B.; Branco, P.S.; Varma, R.S. Nano-magnetite $\left(\mathrm{Fe}_{3} \mathrm{O}_{4}\right)$ as a support for recyclable catalysts in the development of sustainable methodologies. Chem. Soc. Rev. 2013, 42, 3371-3393.

2. Gawande, M.B.; Bonifacio, V.D.B.; Varma, R.S.; Nogueira, I.D.; Bundaleski, N.; Ghumman, C.A.A.; Teodoro, O.M.N.D.; Branco, P.S. Magnetically recyclable magnetite-ceria (Nanocat-Fe-Ce) nanocatalyst-Applications in multicomponent reactions under benign conditions. Green Chem. 2013, 15, 1226-1231.

3. Gawande, M.B.; Guo, H.; Rathi, A.K.; Branco, P.S.; Chen, Y.; Varma, R.S.; Peng, D.-L. First application of core-shell Ag@Ni magnetic nanocatalyst for transfer hydrogenation reactions of aromatic nitro and carbonyl compounds. RSC $A d v$. 2013, 3, 1050-1054. 
4. Vaddula, B.R.; Saha, A.; Leazer, J.; Varma, R.S. A simple and facile Heck-type arylation of alkenes with diaryliodonium salts using magnetically recoverable Pd-catalyst. Green Chem. 2012, 14, 2133-2136.

5. Baig, R.B.N.; Varma, R.S. A highly active and magnetically retrievable nanoferrite-DOPA-copper catalyst for the coupling of thiophenols with aryl halides. Chem. Commun. 2012, 48, 2582-2584.

6. Polshettiwar, V.; Baruwati, B.; Varma, R.S. Nanoparticle-supported and magnetically recoverable nickel catalyst: A robust and economic hydrogenation and transfer hydrogenation protocol. Green Chem. 2009, 11, 127-131.

7. Baruwati, B.; Polshettiwar, V.; Varma, R.S. Magnetically recoverable supported ruthenium catalyst for hydrogenation of alkynes and transfer hydrogenation of carbonyl compounds. Tetrahedron Lett. 2009, 50, 1215-1218.

8. Gawande, M.B.; Rathi, A.; Nogueira, I.D.; Varma, R.S.; Branco, P.S. Magnetite-supported sulfonic acid: A retrievable nanocatalyst for Ritter reaction and multicomponent reactions. Green Chem. 2013, 15, 1895-1899.

9. Reddy, L.H.; Arias, J.L.; Nicolas, J.; Couvreur, P. Magnetic nanoparticles: Design and characterization, toxicity and biocompatibility, pharmaceutical and biomedical applications. Chem. Rev. 2012, 112, 5818-5878.

10. Gawande, M.B.; Rathi, A.; Nogueira, I.D.; Ghumman, C.A.A.; Bundaleski, N.; Teodoro, O.M.N.D.; Branco, P.S. A recyclable ferrite-Co magnetic nanocatalyst for the oxidation of alcohols to carbonyl compounds. ChemPlusChem 2012, 77, 865-871.

11. Gawande, M.B.; Branco, P.S.; Nogueira, I.D.; Ghumman, C.A.A.; Bundaleski, N.; Santos, A.; Teodoro, O.M.N.D.; Luque, R. Catalytic applications of a versatile magnetically separable Fe-Mo (Nanocat-Fe-Mo) nanocatalyst. Green Chem. 2013, 15, 682-689.

12. Zhang, D.; Zhou, C.; Sun, Z.; Wu, L.-Z.; Tung, C.-H.; Zhang, T. Magnetically recyclable nanocatalysts (MRNCs): A versatile integration of high catalytic activity and facile recovery. Nanoscale 2012, 4, 6244-6255.

13. Cano, R.; Yus, M.; Ramon, D.J. First practical cross-alkylation of primary alcohols with a new and recyclable impregnated iridium on magnetite catalyst. Chem. Commun. 2012, 48, 7628-7630.

14. Zeng, T.Q.; Yang, L.; Hudson, R.; Song, G.H.; Moores, A.R.; Li, C.J. Fe ${ }_{3} \mathrm{O}_{4}$ nanoparticle-supported copper(I) pybox catalyst: Magnetically recoverable catalyst for enantioselective direct-addition of terminal alkynes to imines. Org. Lett. 2011, 13, 442-445.

15. Schatz, A.; Hager, M.; Reiser, O. $\mathrm{Cu}(\mathrm{II})$-Azabis(oxazoline)-complexes immobilized on superparamagnetic magnetite@silica-nanoparticles: A highly selective and recyclable catalyst for the kinetic resolution of 1,2-diols. Adv. Funct. Mater. 2009, 19, 2109-2115.

16. Gawande, M.B.; Rathi, A.K.; Branco, P.S.; Nogueira, I.D.; Velhinho, A.; Shrikhande, J.J.; Indulkar, U.U.; Jayaram, R.V.; Ghumman, C.A.A.; Bundaleski, N.; et al. Regio- and chemoselective reduction of nitroarenes and carbonyl compounds over recyclable magnetic ferrite-nickel nanoparticles $\left(\mathrm{Fe}_{3} \mathrm{O}_{4}-\mathrm{Ni}\right)$ by using glycerol as a hydrogen source. Chem. Eur. J. 2012, 18, 12628-12632.

17. Gawande, M.B.; Velhinho, A.; Nogueira, I.D.; Ghumman, C.A.A.; Teodoro, O.M.N.D.; Branco, P.S. A facile synthesis of cysteine-ferrite magnetic nanoparticles for application in multicomponent reactions-a sustainable protocol. RSC Adv. 2012, 2, 6144-6149. 
18. Anastas, P.; Eghbali, N. Green chemistry: Principles and practice. Chem. Soc. Rev. 2010, 39, 301-312.

19. Zhang, Q.; Su, H.; Luo, J.; Wei, Y. "Click” magnetic nanoparticle-supported palladium catalyst: A phosphine-free, highly efficient and magnetically recoverable catalyst for Suzuki-Miyaura coupling reactions. Catal. Sci. Technol. 2013, 3, 235-243.

20. Hudson, R.; Riviere, A.; Cirtiu, C.M.; Luska, K.L.; Moores, A. Iron-iron oxide core-shell nanoparticles are active and magnetically recyclable olefin and alkyne hydrogenation catalysts in protic and aqueous media. Chem. Commun. 2012, 48, 3360-3362.

21. Gawande, M.B.; Bonifacio, V.D.B.; Luque, R.; Branco, P.S.; Varma, R.S. Benign by design: Catalyst-free in-water, on-water green chemical methodologies in organic synthesis. Chem. Soc. Rev. 2013, 42, 5522-5551.

22. Gawande, M.B.; Branco, P.S. An efficient and expeditious Fmoc protection of amines and amino acids in aqueous media. Green Chem. 2011, 13, 3355-3359.

23. Polshettiwar, V.; Varma, R.S. Aqueous microwave chemistry: A clean and green synthetic tool for rapid drug discovery. Chem. Soc. Rev. 2008, 37, 1546-1557.

24. Simon, M.-O.; Li, C.-J. Green chemistry oriented organic synthesis in water. Chem. Soc. Rev 2012, 41, 1415-1427.

25. Polshettiwar, V.; Varma, R.S. Microwave-assisted organic synthesis and transformations using benign reaction media. Acc. Chem. Res. 2008, 41, 629-639.

26. Polshettiwar, V.; Baruwati, B.; Varma, R.S. Magnetic nanoparticle-supported glutathione: A conceptually sustainable organocatalyst. Chem. Commun. 2009, 1837-1839.

27. Polshettiwar, V.; Varma, R.S. Nanoparticle-supported and magnetically recoverable ruthenium hydroxide catalyst: Efficient hydration of nitriles to amides in aqueous medium. Chem. Eur. J. 2009, 15, 1582-1586.

28. Garcia-Garrido, S.E.; Francos, J.; Cadierno, V.; Basset, J.M.; Polshettiwar, V. Chemistry by nanocatalysis: First example of a solid-supported rapta complex for organic reactions in aqueous medium. ChemSusChem 2011, 4, 104-111.

29. Hildebrand, H.; Mackenzie, K.; Kopinke, F.-D. Highly active pd-on-magnetite nanocatalysts for aqueous phase hydrodechlorination reactions. Environ. Sci. Technol. 2009, 43, 3254-3259.

30. Rezaeifard, A.; Jafarpour, M.; Farshid, P.; Naeimi, A. Nanomagnet-supported partially brominated manganese-porphyrin as a promising catalyst for the selective heterogeneous oxidation of hydrocarbons and sulfides in water. Eur. J. Inorg. Chem. 2012, 2012, 5515-5524.

31. Baig, R.B.N.; Varma, R.S. Magnetically retrievable catalysts for organic synthesis. Chem. Commun. 2013, 49, 752-770.

32. Polshettiwar, V.; Varma, R.S. Nano-organocatalyst: Magnetically retrievable ferrite-anchored glutathione for microwave-assisted Paal-Knorr reaction, aza-Michael addition, and pyrazole synthesis. Tetrahedron 2010, 66, 1091-1097.

33. Dydio, P.; Lichosyt, D.; Jurczak, J. Amide- and urea-functionalized pyrroles and benzopyrroles as synthetic, neutral anion receptors. Chem. Soc. Rev. 2011, 40, 2971-2985.

34. Ma, F.-P.; Li, P.-H.; Li, B.-L.; Mo, L.-P.; Liu, N.; Kang, H.-J.; Liu, Y.-N.; Zhang, Z.-H. A recyclable magnetic nanoparticles supported antimony catalyst for the synthesis of $N$-substituted pyrroles in water. Appl. Catal. A 2013, 457, 34-41. 
35. Wang, B.G.; Ma, B.C.; Wang, Q.; Wang, W. Superparamagnetic nanoparticle-supported (s)-diphenylprolinol trimethylsilyl ether as a recyclable catalyst for asymmetric michael addition in water. Adv. Synth. Catal. 2010, 352, 2923-2928.

36. Saha, A.; Leazer, J.; Varma, R.S. $O$-Allylation of phenols with allylic acetates in aqueous media using a magnetically separable catalytic system. Green Chem. 2012, 14, 67-71.

37. Tanaka, S.; Saburi, H.; Ishibashi, Y.; Kitamura, M. (CpRuPF6)-P-II/quinaldic acid-catalyzed chemoselective allyl ether cleavage. A simple and practical method for hydroxyl deprotection. Org. Lett. 2004, 6, 1873-1875.

38. Williamson, A.W. XXII.-On etherification. J. Chem. Soc. 1852, 4, 229-239.

39. Rajabi, F.; Karimi, N.; Saidi, M.R.; Primo, A.; Varma, R.S.; Luque, R. Unprecedented selective oxidation of styrene derivatives using a supported iron oxide nanocatalyst in aqueous medium. Adv. Synth. Catal.2012, 354, 1707-1711.

40. Shipley, H.J.; Engates, K.E.; Guettner, A.M. Study of iron oxide nanoparticles in soil for remediation of arsenic. J. Nanopart. Res.2011, 13, 2387-2397.

41. Beygzadeh, M.; Alizadeh, A.; Khodaei, M.M.; Kordestani, D. Biguanide/Pd(OAc) 2 immobilized on magnetic nanoparticle as a recyclable catalyst for the heterogeneous Suzuki reaction in aqueous media. Catal. Commun. 2013, 32, 86-91.

42. Miyaura, N.; Suzuki, A. Palladium-catalyzed cross-coupling reactions of organoboron compounds. Chem. Rev. 1995, 95, 2457-2483.

43. Yin, J.J.; Rainka, M.P.; Zhang, X.X.; Buchwald, S.L. A highly active Suzuki catalyst for the synthesis of sterically hindered biaryls: Novel ligand coordination. J. Am. Chem. Soc. 2002, 124, 1162-1163.

44. Deng, J.; Mo, L.-P.; Zhao, F.-Y.; Zhang, Z.-H.; Liu, S.-X. One-pot, three-component synthesis of a library of spirooxindole-pyrimidines catalyzed by magnetic nanoparticle supported dodecyl benzenesulfonic acid in aqueous media. ACS Comb. Sci. 2012, 14, 335-341.

45. Sheldon, R.A.; Kochi, J.K. Metal-Catalysed Oxidation of Organic Compounds; Academic Press: New York, NY, USA, 1981.

46. Hudlicky, M. Oxidation in Organic Chemsitry (ACS Monograph Series); ACS: Washington, DC, USA, 1990.

47. Aurich, H.G.; Hahn, K.; Stork, K.; Weiss, W. Aminyl oxides (nitroxides). 24. Empirical determination of spin-density distribution in aminyl oxides. Tetrahedron 1977, 33, 969-975.

48. Karimi, B.; Farhangi, E. A highly recyclable magnetic core-shell nanoparticle-supported tempo catalyst for efficient metal- and halogen-free aerobic oxidation of alcohols in water. Chem. Eur. J. 2011, 17, 6056-6060.

49. Kiasat, A.R.; Nazari, S. Magnetic nanoparticles grafted with beta-cyclodextrin-polyurethane polymer as a novel nanomagnetic polymer brush catalyst for nucleophilic substitution reactions of benzyl halides in water. J. Mol. Catal. A 2012, 365, 80-86.

50. Can, K.; Ozmen, M.; Ersoz, M. Immobilization of albumin on aminosilane modified superparamagnetic magnetite nanoparticles and its characterization. Colloids Surf. B 2009, 71, 154-159.

51. Fujii, S.; Hamasaki, H.; Abe, H.; Yamanaka, S.; Ohtaka, A.; Nakamura, E.; Nakamura, Y. One-step synthesis of magnetic iron-conducting polymer-palladium ternary nanocomposite microspheres with applications as a recyclable catalyst. J. Mater. Chem. A 2013, 1, 4427-4430. 
52. Kale, S.R.; Kahandal, S.S.; Gawande, M.B.; Jayaram, R.V. Magnetically recyclable $\gamma-\mathrm{Fe}_{2} \mathrm{O}_{3}-\mathrm{HAP}$ nanoparticles for the cycloaddition reaction of alkynes, halides and azides in aqueous media. RSC Adv. 2013, 3, 8184-8192.

53. Meldal, M.; Tornoe, C.W. Cu-catalyzed azide-alkyne cycloaddition. Chem. Rev. 2008, 108, 2952-3015.

54. Kolb, H.C.; Finn, M.G.; Sharpless, K.B. Click chemistry: Diverse chemical function from a few good reactions. Angew. Chem Int. Ed. 2001, 40, 2004-2021.

55. Baig, R.B.N.; Varma, R.S. A highly active magnetically recoverable nano ferrite-glutathione-copper (nano-FGT-Cu) catalyst for Huisgen 1,3-dipolar cycloadditions. Green Chem. 2012, 14, 625-632.

56. Hudson, R.; Li, C.J.; Moores, A. Magnetic copper-iron nanoparticles as simple heterogeneous catalysts for the azide-alkyne click reaction in water. Green Chem. 2012, 14, 622-624.

57. Yeo, K.M.; Lee, S.I.; Lee, Y.T.; Chung, Y.K.; Lee, I.S. Core-satellite heterostruture of $\mathrm{Fe}_{3} \mathrm{O}_{4}-\mathrm{Pd}$ nanocomposite: Selective and magnetically recyclable catalyst for decarboxylative coupling reaction in aqueous media. Chem. Lett. 2008, 37, 116-117.

58. Mori, K.; Yoshioka, N.; Kondo, Y.; Takeuchi, T.; Yamashita, H. Catalytically active, magnetically separable, and water-soluble FePt nanoparticles modified with cyclodextrin for aqueous hydrogenation reactions. Green Chem. 2009, 11, 1337-1342.

59. Sun, Y.; Liu, G.; Gu, H.; Huang, T.; Zhang, Y.; Li, H. Magnetically recoverable $\mathrm{SiO}_{2}$-coated $\mathrm{Fe}_{3} \mathrm{O}_{4}$ nanoparticles: A new platform for asymmetric transfer hydrogenation of aromatic ketones in aqueous medium. Chem. Commun. 2011, 47, 2583-2585.

60. Rezaeifard, A.; Jafarpour, M.; Naeimi, A.; Haddad, R. Aqueous heterogeneous oxygenation of hydrocarbons and sulfides catalyzed by recoverable magnetite nanoparticles coated with copper(II) phthalocyanine. Green Chem. 2012, 14, 3386-3394.

(C) 2013 by the authors; licensee MDPI, Basel, Switzerland. This article is an open access article distributed under the terms and conditions of the Creative Commons Attribution license (http://creativecommons.org/licenses/by/3.0/). 